\title{
A Missa de São Nicolau, de Almeida Prado, na Confluência das Opções Estéticas dos Anos 80
}

\author{
Carole GubernikofF
}

A Missa de São Nicolau é uma obra chave na produção de Almeida Prado e ilustra os impasses estéticos que se apresentaram aos compositores brasileiros ao longo da segunda metade do século. Composta entre 1985 e 1986, situa-se na confluência das reavaliações técnicas e estéticas que atravessaram os anos 80 .

\section{Antecedentes}

\subsection{Entre o nacionalismo e a vanguarda}

A trajetória artística de Almeida Prado exemplifica alguns dos impasses que se impuseram às possibilidades de expressão artística dentro do cenário da música brasilcira contemporânea nos últimos anos.

O início de sua formação, sob a orientação de Dinorah de Carvalho, Osvaldo Lacerda e Camargo Guarnieri, foi marcado pelo tradicionalismo e baseado em cânones clássicos da composição, resistentes a qualquer inovação. Esta formação deixará marcas perenes na concepção composicional de Almeida Prado, tanto pela qualidade dos ensinamentos de Camargo Guarnieri, quanto pela subseqüente rebelião aos dogmatismos de uma formação de feitio nacionalista. Em seu depoimento na série de debates Encontros/Desencontros ${ }^{1}$, realizados durante a XI Bienal de Música Contemporânea, em 1995, ele explicitou suas resistências em

1. C. Gubernikoff (org.), 1996, Encontros/Desencontros, Debates da XI Bienal de Música Brasileira Contemporânea, Rio de Janeiro, Uni-Rio/Faperj. 
aceitar o nacionalismo como dogma. Nesta ocasião, referiu-se ironicamente ao Ensaio sobre a Música Brasileira ${ }^{2}$, leitura obrigatória para os alunos de Camargo Guarnieri, como "a Bíblia". De acordo com seu depoimento, os alunos eram estimulados a seguir os exemplos musicais do livro na forma de exercícios de composição.

Movido pela curiosidade e pela necessidade de encontrar novas formas de expressão, mais de acordo com a sensibilidade estética de seu tempo, ele viajou para a França com recursos da premiação de sua obra Pequenos Funerais Cantantes no Festival da Guanabara de 1969. Em suas próprias palavras, ele foi "procurar as informações que considerava importantes", apesar de já ter experimentado formas de expressão menos convencionais, utilizando quase que intuitivamente séries dodecafônicas, clusters, glissandi e experimentando texturas. Este tipo de "captação" de técnicas permaneceu como uma das marcas estilísticas de seu trabalho, muitas vezes tendo-as empregado antes de qualquer treinamento formal.

Em Paris, procurou as duas grandes vertentes do ensino de composição da época: Olivier Messiaen, decano da vanguarda européia - mestre, entre outros, de Pierre Boulez, Karlheinz Stockhausen e Nadia Boulanger, da ala conservadora. A dualidade já presente no Brasil, a formação convencional e a atração intuitiva pelas qualidades expressivas de procedimentos mais "experimentais" repetiram-se, desta forma, na França.

\subsection{O ensino de Messiaen}

O ensino de Messiaen ${ }^{3}$ não pode ser considerado "experimental", uma vez que era extremamente rigoroso. A grande atração que ele exercia sobre os jovens compositores devia-se à originalidade de sua abordagem, ao interesse por tradições culturais não européias e pelo inconformismo com as fórmulas "de conservatório".

Os ensinamentos de Messiaen deixaram marcas profundas na obra de Almeida Prado em vários aspectos. As gerações de discípulos que o antecederam, entre os quais encontramos Pierre Boulez, Stockhausen e

2. M. Andrade, Ensaio sobre a Música Brasileira, São Paulo, Livraria Martins/INL, 1927.

3. J. Boivin, La classe de Messiaen, Paris, Christian Bourgois, 1994. 
Pousseur, estavam interessadas nas técnicas de escrita automática, através da repetição e permutação de células motívicas. Para Almeida Prado, mais do que no plano técnico da écriture, da escrita composicional, as identificações deram-se em outros planos, sendo que um deles antecede sua ida a Paris: a religiosidade católica em suas manifestações místicas.

A sensibilidade religiosa em Olivier Messiaen atravessa todo o seu universo sonoro-musical e deixa marcas na sua concepção técnico-expressiva ${ }^{4}$. No aspecto harmônico, ele é literalmente atravessado pela espiritualidade através de uma sinestesia de cores e sons. Para Messiaen, as formações sonoras possuem qualidades próprias, ele as ouvia/via como blocos colorísticos sonoros moventes. Baseado neste preceito sensível, ele desprezava o dodecafonismo porque seu efeito colorístico correspondia a uma espécie de tom "cinza", sem brilho, onde todas as relações encontram-se misturadas e sempre presentes. A harmonia, entendida como filtragem de uma "totalidade" sonora, como se fosse um campo de indeterminação que ganha contornos através da sensibilidade (afectus e perceptus $)^{5}$, é fundamental para a compreensão das técnicas composicionais desenvolvidas por Messiaen. A idéia central é a da "limitação, dos impasses, das impossibilidades de continuar", como o compositor francês Jean Barraqué, discípulo de Messiaen, descreveu o final de $\mathrm{La}$ Mer de Debussy6.

As idéias de limitação, de não infinitude, podem ser encontradas em vários aspectos da obra de Messiaen e foram formalizadas principalmente nos modos de transposição limitada e nos ritmos não retrogradáveis. Do ponto de vista da lógica composicional, esta concepção contribuiu para a criação de um universo musical de caráter estático e circular, baseado na permutabilidade dos elementos. A aplicação desta permutabilidade limitada a outros parâmetros do som, as durações e as intensidades, além das alturas, como havia feito o dodecafonismo, redundaram nos diversos tipos de serialismo integral dos anos $50^{7}$.

4. B. Massin, Olivier Messiaen: une poétique du merveilleux, Aix en Provence, Alinéa, 1989.

5. Ver G. Deleuze \& F. Guattari, Qu'est-ce que la philosophie, Paris, Himit, 1991.

6. Jean Barraque, "Analyse musicale de La Mer, de Claude Debussy", Révue d'Analyse Musicale 12, Paris SFAM.

7. A obra de referência a este respeito é Modos de Valor e Intensidade, de Olivier 
A gradativa mudança nas concepções de tempo musical, entretanto, já vinha se esboçando desde o início do século em compositores de tendências estéticas diferentes: em algumas obras de Debussy, onde muitas vezes a função tonal harmônica é substituída pelo jogo timbrístico colorístico dos acordes; em obras expressionistas de Anton Webern, onde os campos sonoros criados pela utilização do total cromático, em relações de dissonância sem resolução, suspendem a direcionalidade; e nas formas em mosaico de Igor Stravinsky.

Do ponto de vista do fluxo temporal, o compositor alemão Karlheinz Stockhausen, principalmente na década dos sessenta, trouxe uma nova concepção do fluxo sonoro-temporal, as chamadas "Formas-Momento" onde cada momento corresponde a "estados" sem relação de linearidade nem de resolução de expectativas harmônicas entre $\mathbf{s i}^{8}$.

Quando Almeida Prado chegou à França em 1970, o apogeu do serialismo integral já havia passado e os compositores jovens que participavam das classes de Messiaen procuravam maneiras de se expressar que levassem em conta não apenas as relações abstratas, mas também os fatores perceptivos. Para esta geração, da qual fazem parte Almeida Prado e Tristan Murail, o maior ensinamento de Messiaen foi de caráter harmônico-timbrístico.

O conceito de harmonia timbrística ou, ainda, de harmonia associada a cores mais do que a intervalos, é crucial para o entendimento da posição adotada por esta geração de discípulos de Messiaen. Conforme podemos verificar no seu livro, Technique de mon Langage $\mathrm{Mu}$ sical, o conceito de harmonia de Messiaen consiste numa interrelação entre os modos de transposição limitada e os acordes resultantes. Apesar dele não apresentar nenhuma relação entre os acordes e suas funções, como seria necessário numa teoria tonal, permanece uma diferença qualitativa fundamental para o entendimento da diferença entre este sistema e outros sistemas que empregam a permutação de célula, como o serialismo, por exemplo. Uma coleção ${ }^{9}$ de sete notas

Messiaen, que afetou grandemente os compositores europeus da época, por mostrar a possibilidade de serialização não apenas as notas, mas também as durações e intensidades.

8. A este respeito, consultar J. Kramer, The Time of Music, New York, Schirmers, 1988 ou C. Gubernikoff, Música e Representação: das Durações aos Tempos, tese de doutorado, Rio de Janeiro, UFRJ, 1993.

9. Coleção, do inglês collection, termo utilizado pela set theory, teoria dos conjun- 
pode ter as mesmas notas e intervalos que uma escala. Entretanto, a escala ou modo parte de uma nota fundamental da qual ela "emana". A coleção aceita qualquer ordenação. Os modos de transposição limitada de Messiaen têm como característica a limitação. Ou seja, seu caráter só aceita determinado número de transposições e é isto que faz com que tenham qualidades próprias.

Modos, escalas e acordes estão interrelacionados. Os acordes diletos de Messiaen são "franceses", ou seja, partem do princípio da sexta acrescentada, o acorde de six ajoutée de Rameau. Se considerarmos o acorde dó, mi, sol, lá, sua fundamental é dó, e não lá, como se poderia supor pela justaposição de terças. Ora, esta diferença é determinada não pelos intervalos, mas pelo caráter do acorde.

É justamente este caráter timbrístico de bases "naturais", a nota que está no baixo determinando a série dos parciais harmônicos, que vai marcar e influenciar os discípulos do início dos anos 70. Os chamados "acordes de ressonância" de Messiaen, que ele considera como "audíveis por um ouvido refinado", partem do princípio da série dos harmônicos e são construídos praticamente sobre os parciais de 2 a $11^{10}$.

\subsection{Cartas celestes, o deslumbramento dos timbres}

Na década de 70, a obra mais marcante, composta sob o impacto destas influências, foi o primeiro volume das Cartas Celestes.

É uma obra extremamente descritiva, baseada no Atlas Celeste do Brasil publicado por Ronaldo Rogério de Freitas Mourão ${ }^{11}$. Ali, dois fatores interrelacionados são extremamente importantes: a representação dos momentos e aspectos do firmamento e o "banco de acordes" usado como limitação de possibilidades e como paletas do "quadro".

O princípio composicional de Cartas Celestes é extremamente simples e eficaz. O material harmônico de toda a peça se constitui de acor-

tos, para designar um número finito de classe de nota e de classe de intervalos utilizados como material estruturante.

10. Devidamente "temperados", podemos observar que a série harmônica, de 2 a 11, resulta no acorde Dó, sol, dó, mi, sol, (sib), dó, re, mi, fá\#.; e as notas da chamada escala acústica, de 8 a a 16, correspondem a dó, ré, mi, fá\#, sol, lá, lá\#, si, dó.

11. Ronaldo Rogério de Freitas Mourão, Carta Celeste do Brasil, Rio de Janeiro, Francisco Alves. 
des pré estabelecidos, de maior ou menor densidade, cada um "representando" uma constelação, ou corpo celeste ou uma entidade qualquer, como as letras do alfabeto grego, que serão utilizados de acordo com critérios de maior por menor clareza, luminosidade, transparência, densidade.

A questão da luz/timbre é provavelmente uma das mais importantes a se observar em Cartas Celestes. Vários materiais-textura, registro, ritmo, harmonia, dinâmica são combinados com o objetivo de descrever as luminosidades do céu. Com Almeida Prado, o piano deixa de ser um instrumento mono-timbrístico e passa a produzir uma gama variada e impressionante de timbres. [...]

...24 acordes criados, representados pelas 24 letras do alfabeto grego, os quais o compositor utiliza para "representar sonoramente cada estrela nas constelações" (Almeida Prado, Prefácio de Cartas Celestes I). Estes acordes, cada um como uma entidade fixa, sem inversões ou transposições, vão sugerir impressões de luminosidades das mais variadas, indo desde a transparência das quintas até a opacidade dos clusters. Observa-se também que o primeiro e o último acordes, alpha e ômega, respectivamente, possuem as mesmas notas, mas dispostas de maneira diferente, o que sugere uma luminosidade diversa (fato que o autor vai explorar em Alpha-Piscium, combinando os dois acordes). Isso demonstra que os fatores registro e posição são tão importantes quanto os intervalos harmônicos constituintes dos acordes ${ }^{12}$.

O que chama a atenção neste texto é que os acordes devem ser usados na posição fixa em que estão, sem inversão ou transposição, cada um representando uma luminosidade específica que entrará na composição como tonalidades que, combinadas entre si, resultarão em zonas de maior ou menor ressonância.

Esta técnica harmônica foi descrita na sua tese de doutorado ${ }^{13}$.

Meu sistema deveria então significar um esforço de combinar a experiência atonal com o uso racional dos harmônicos superiores e inferiores, criando Zonas de Ressonância.

O Sistema Organizado de Ressonâncias se divide em várias zonas

1. Zona de ressonância explícita.

1a. Quando usamos racionalmente os harmônicos superiores ou inferiores.

1b. Notas estranhas são consideradas invasoras, ornamentais.

2. Zona de ressonância implícita.

12. Daniel Rousseau, "Cartas Celestes de Almeida Prado", in Relatório Parcial da Pesquisa. Implicações Estéticas na Música Brasileira Contemporânea nos anos 70 e 80: Almeida Prado, Gilberto Mendes e Rodolfo Caesar, ao CNPQ, 1995.

13. J. A. Almeida Prado, Cartas Celestes, Uma Uranografia Sonora Geradora de Novos Processos Composicionais (Tese Doutorado), Campinas, Unicamp, 1984. 
2a. Numa passagem atonal, notas que se encontram dentro da Zona de Ressonância são introduzidas no sentido de atrair a percepção.

3. Zona de ressonância múltipla.

3a. O uso de acordes simultâneos cria um turbilhão de ressonâncias, não distinguíveis pelos ouvidos.

4. Zonas não ressonantes.

4a. Empregar racionalmente acordes e elementos melódicos, simples ou polifônicos, que não ressoam absolutamente, criando regiões opacas, zonas neutras que são vitais pela necessidade de contraste.

A redundância seria, desta forma, um fator importante para gerar ressonâncias ${ }^{14}$.

Durante a década dos 80 , sua obra vai sendo gradativamente permeada por todas as influências pelas quais passou ao longo da vida, sem necessidade de rejeição. Esta atitude de aceitação e de mistura marca a sua produção, que passará a ser norteada não pelos princípios da novidade, mas por um princípio de qualidade que ele define como "soar bem".

Esta forma de valoração de um produto artístico pode parecer extremamente subjetiva e seus critérios de avaliação difíceis de serem definidos. Dependem, em grande medida, da avaliação sensível, de uma "correção pelo ouvido", onde a escuta do compositor é a medida de valor da obra em curso. Esta escuta, que pódemos considerar "ingênua", no sentido positivo com que alguns cientistas a empregam, é que, acreditamos, foi responsável pelas decisões composicionais da Missa de São Nicolau ${ }^{15}$.

\section{A Missa de São Nicolau}

\subsection{A missa}

A Missa São Nicolau, composta no ano de 1985-1986, é um marco na trajetória de Almeida Prado. De acordo com depoimentos do compo-

14. Prado, 1984 , p. 559. Esta observação final se aplica a uma obra para piano. O efeito de ressonância por saturação da repetição não funciona nem vocalmente, nem orquestralmente (N.A).

15. O cientista laureado com prêmio Nobel, Sir Peter Medawer, citado pelo compositor e teórico Georges Perle diz: "A observação é o ato generativo da descoberta científica. Apesar de todas as suas aberrações, devemos confiar nas evidências apresen- 
sitor, ele teve de se defrontar com limitações pragmáticas que impuseram à composição uma série de restrições e desafios que, ao serem solucionados, foram colaborando para os contornos estéticos da obra.

Um destes fatores era a forma musical "Missa", que não deve ser confundida com o ritual de celebração de uma missa, apesar de seguir a ordem cronológica e dramática dos momentos. Uma Missa é, normalmente, em forma de cantata ou oratório, com orquestra, coro e solistas. Cinco movimentos podem ser considerados o Ordinário da missa ou suas partes fixas: Kyrie, Gloria, Credo, Sanctus e Agnus Dei. A forma musical Missa se consolidou no século XIV e a primeira missa composta por um único autor foi a Messe de Notre Dame, de Guillaume de Machaut.

O estilo da música religiosa adotada mesmo nos dias de hoje, entretanto, remete àquele criado pelo compositor Palestrina, no século XVI, para atender as exigências de compreensibilidade impostas pelo Concílio de Trento. Não só o texto, como o caráter de cada seção e o tipo de polifonia vocal foram então definidos.

Almeida Prado optou pela forma de oratório, com quatro cantores solistas, coro SATB e orquestra, inscrevendo-se na longa tradição de música religiosa. Podemos rastrear influências que vão desde a Missa Papa Marcelo, de Palestrina, Missa em Si menor de Bach, a Missa Solene de Beethoven, o Requiem de Verdi, até a música religiosa de Messiaen.

\subsection{Orquestração e instrumentação}

A formação instrumental é clássica: cordas, violinos, violas, violoncelos e contrabaixos; madeiras, 2 flautas, 2 oboés, 2 clarinetes e 2 fagotes; metais, 2 trompas, 2 trompetes e 2 trombones; coro e quarteto solista SATB; sinos tubulares e tímpanos.

Sinos suspensos, apesar de aparecerem esporadicamente como solistas, são o fio condutor dramático da obra. Eles "anunciam" os temas, colaboram na construção dos pontos culminantes, tocam as notas fundamentais das seções, expõem material intervalar e escalares de algumas

tadas pelos sentidos, desde que observemos a natureza como as crianças, sem preconceitos ou pré-concepções, com a visão clara e ingênua que os adultos perderam e que os cientistas se esforçam em recuperar" (G. Perle, The Listening Composer, Los Angeles, Un. of California, 1990). 
seções. Tanto pelo material do seu corpo, quanto pelo formato e pelo ataque percussivo, este instrumento não produz uma afinação justa, produzindo um espectro ligeiramente inarmônico, com os primeiros parciais soando mais que a fundamental. Esta característica faz com que o espectro resultante dos parciais tenha uma forma distorcida, alterando a percepção tanto do temperamento quanto da afinação. Por estas características, o sino transformou-se no instrumento de referência dos compositores espectrais. Outro aspecto que merece atenção é a função social dos sinos nas sociedades de tradição européia. Além de servir como "marcador" da passagem do tempo, anunciando as horas e os eventos principais da comunidade, os sinos ganharam vários significados musicais através de sua utilização em repertório consagrado.

A "desafinação" dos sinos já havia sido utilizada com efeitos dramáticos na Sinfonia Fantástica de Hector Berlioz, de 1830, com o mesmo sentido de sinalizar algo terrível ou da ordem do maravilhoso e extraordinário. Nesta sinfonia, os sinos são usados para sublinhar tanto o terrível e noturno quanto a chegada da manhã.

Almeida Prado explora os dois sentidos de sinos: o físico, por suas qualidades timbrísticas e pela forma de ataque, e a dramático, pelas conotações já consolidadas.

$\mathrm{Na}$ vertente física da qualidade do som, a orquestração valoriza os metais e os tímpanos, que têm praticamente a mesma função que os sinos na condução dramática. Na orquestração, os sinos apontam para duas direções sonoras: a dos metais - pela ressonância - e a dos tímpanos - pela forma de ataque.

As madeiras e as cordas completam a orquestração, muitas vezes complementando-se, principalmente nos aglomerados sonoros agudos, onde a harmonização tende a ser mais estreita e dissonante, cabendo a eles a realização das passagens mais complexas do ponto de vista da simultaneidade de blocos sonoros.

A parte para coral é composta com muito cuidado, no sentido de não utilizar texturas muito complexas ou harmonicamente dissonantes, que dificultariam a entonação correta e realização expressiva. Na maior parte do tempo, a escrita coral emprega as texturas tradicionais, com poucas exceções.

As vozes solistas, ao contrário, têm uma longa tradição de virtuosismo vocal e, guardadas as extensões naturais das vozes, podem receber uma 
escrita mais complexa. Entretanto, mesmo elas se encontram dentro de uma tessitura confortável, sem recorrer a formas de ataque não convencionais.

Logo, encontramos pelo menos três níveis de dificuldade, três planos sonoros que vão distribuir, de maneira diferenciada e complementar, a textura musical. O nível das notas graves, que apóiam a harmonia, muitas vezes em notas longas sustentadas, principalmente por conta do trombone, do contrabaixo e do violoncelo. O nível médio, ocupado por tríades e densidades transparentes, onde se encontram principalmente o coral, as cordas e os sopros, e o nível agudo, onde a densidade se estreita e adensa e os acordes tornam-se mais complexos e cromáticos. Este princípio de distribuição dos registros e das densidades baseia-se no princípio de que a música deve respeitar a natureza do som, como vimos anteriormente, quando discutimos os acordes "de ressonância" de Messiaen. Isto não impede que Almeida Prado utilize massas densas de clusters em todos os registros com o intuito de filtrá-los, de extrair da massa sonora um "acorde perfeito".

\subsection{Harmonia e transtonalismo na Missa de São Nicolau}

O principal recurso harmônico utilizado por Almeida Prado é o que ele chama de transtonalidade. Ele considera esta técnica semelhante, em seus princípios, à empregada pelos compositores da escola espectral, cujos maiores representantes são Tristan Murail e Gerard Grisey, ambos contemporâneos da classe de composição de Messiaen. Entretanto, a Missa está longe de ser uma obra espectral, no sentido em que foi desenvolvido por estes compositores. Os franceses recorreram a complexas análises de espectros de instrumentos, feitas com o auxílio do computador, que definem o universo harmônico, os timbres e os procedimentos composicionais. Em algumas obras, o maior interesse é a exploração da transição de um timbre a outro, uma "duplicação" do espectro na massa orquestral, onde cada nota do espectro original é orquestrada. Em Almeida Prado, o princípio genérico de um baixo "condutor", gerador de timbres e harmonias, permanece, mas não os cálculos e as análises de espectro e menos ainda o sentido de "processo" composicional. Este conceito, processus em francês, significando "em processo" ou simplesmente técnica, consiste na construção de uma "passagem" harmônico-timbrística de um modelo de espectro a outro. 
O transtonalismo de Almeida Prado combina a necessidade de uma escuta dirigida pelos baixos, que conduzem a harmonia no sentido tradicional, com vários recursos técnicos utilizados principalmente nos anos 70 e especial atenção à textura. Desta forma, mesmo em seus níveis mais profundos, sua composição nunca abandonou a escrita empírica. Este empirismo é comum entre os compositores brasileiros, que, mesmo quando engajados na militância estética mais radical - como nos caso do grupo "Música Viva" sob a orientação de Hans Joachin Koeelreutter, na década de 40, e dos integrantes do "Manifesto Música Nova", na década de 60 - sempre aplicaram as ortodoxias dodecafônicas ou de vanguarda de forma muito livre, "sem rigor", como eles mesmos gostam de definir.

De um modo geral, na Missa de São Nicolau as várias técnicas composicionais utilizadas prestam-se à expressão do momento, da passagem e da imagem sonora.

\subsection{O plano da obra}

Como já mencionamos anteriormente, o plano da obra segue a subdivisão em cinco movimentos, cada um com uma nota fundamental de referência.

a. Kyrie, Chryste, Kyrie Dó

b. Gloria, laudamus te, qui tollis peccata mundi, cum sancto spirito. Ré

c. Credo, et incarnatus est, crucifixus, et ressurectis $\mathrm{Mi}$

d. Sanctus/hosanna - (Lá?)

e. Agnus Dei - Fá

O plano da Missa é o exemplo da vontade de uma narrativa dramática que encontramos nas obras de Almeida Prado. Cada movimento se constrói sobre centros harmônicos definidos que, grau a grau, guiam a atenção dos ouvintes do centro de polarização que vai de Dó a Fá. Estes passos ascendentes podem corresponder a uma marcha espiritual, uma ascese em que o mistério da missa vai se desenrolando. Estes centros harmônicos não devem ser confundidos com tonalidades no sentido tradicional - a relação das funções de tríades de tônica, dominante e subdominante -, mesmo que encontremos recursos desta técnica utiliza- 
dos quase despudoradamente. Poderíamos dizer que a polarização de determinadas notas, através de resoluções locais de dissonâncias, as progressões harmônicas de sons simultâneos, e não necessariamente de tríades, atraem a atenção do ouvinte numa simulação das técnicas tonais, na qual as funções harmônicas tradicionais nunca ficam claras. Estes procedimentos guiam a audição passo a passo, em bases locais, sem necessidade de inserir cada passagem numa concepção totalizante e sem estarem compreendidas ou remeterem a um sistema genérico ${ }^{16}$.

\subsubsection{Kyrie (Adagio)}

O procedimento do transtonalismo, que se fundamenta na série dos harmônicos, é mais efetivamente utilizado no primeiro grande movimento da Missa, o Kyrie, que segue a forma tradicional em três partes: Kyrie, Christe, Kyrie. A harmonia se constrói a partir da projeção da série de parciais derivadas de um som fundamental. A atenção do ouvinte é conduzida pelas notas do baixo, considerado como som fundamental, tocado principalmente por trombones e contrabaixos, que fazem a condução harmônica. A intenção transtonal localiza-se principalmente nas vozes superiores, que realizam harmonias complexas, baseadas em clusters nas cordas e nas madeiras, à maneira dos harmônicos superiores. Ao coral cabe a região intermediária, ainda em analogia com a série dos harmônicos, que realizam tríades e tétrades, ou aos solistas, que enunciam a escala sobre a qual se baseia a seção. A harmonia predominante é oriunda da chamada escala acústica, que já havia sido utilizada tanto por Bela Bartok, quanto por Messiaen. A "escala acústica", base dos acordes de ressonância de Messiaen, estaria construída sobre os harmônicos superiores na ordem de aparecimento. O material principal do Kyrie é construído sobre um acorde de sétima de dominante com acréscimo de quarta aumentada ou, ainda, com tríade menor, mais sexta acrescentada e quarta aumentada. Estes acordes básicos contêm dois trítonos, que serão explorados tanto nas conduções dos baixos, quanto na formação dos acordes e nos temas melódicos.

16. Na música tonal tradicional, há um sistema que funciona como "referente" genérico, do qual cada obra é uma realização particular. 
Exemplo 1. Materiais escalares e intervalares do Kyrie.

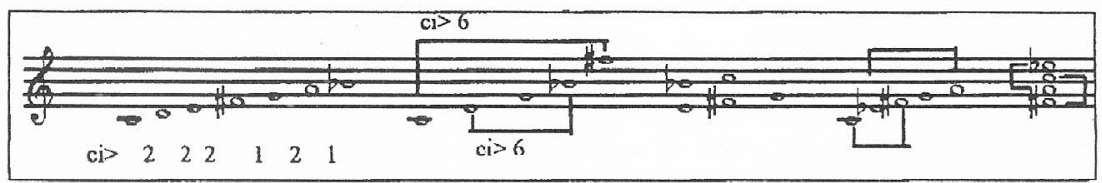

A palavra Kyrie segue a formulação mais tradicional da prosódia, sendo encontrada tanto na Missa Papa Marcelo, de Palestrina, quanto na Missa em Si menor, de Bach. Não consideramos a utilização desta prosódia uma citação ou referência a estas duas obras fundamentais, mas apenas uma imagem de invocação ao Senhor, uma prosódia "natural", que Almeida Prado não reluta em utilizar.

Exemplo 2. Padrão rítmico-prosódico do Kyrie.

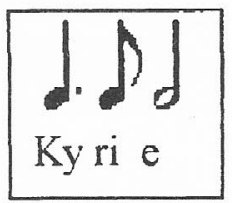

Com estes materiais básicos, após uma introdução dramática, realizada por trombones e trompas, violoncelos e contrabaixos, que apresentam o motivo rítmico sobre as notas do arpejo descendente, o tema do Kyrie, formado de dois trítonos, é apresentado três vezes pelo coro, com mudanças de âmbito e textura, a primeira em uníssono e a última em estilo imitativo até levar ao Christe, que explora aspectos contrastantes em relação ao Kyrie.

Exemplo 3. Notas da introdução.

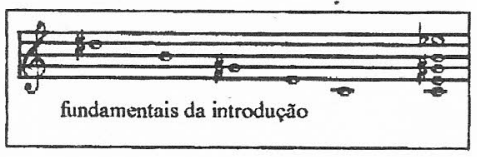


Exemplo 4. Tema sobre dois trítonos.

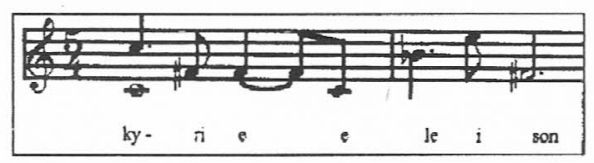

Outro aspecto do interesse dramático e retórico de Almeida Prado podemos encontrar na utilização do material harmônico transtonal. A introdução do Kyrie apresenta uma série de acordes que seguem a construção transtonal, em "resposta" às notas graves dos baixos.

Ao final da primeira seção do Kyrie, a partir do compasso 36, o acorde transtonal sobre a nota Dó no baixo se repete, "preparando" a entrada do Christe. Este último acorde, em suas regiões médias e agudas, contém todas as notas do total cromático, menos as duas que abrem o Christe, a terça menor, si/sol \#.

Exemplo 5. Acorde transtonal de 10 sons.

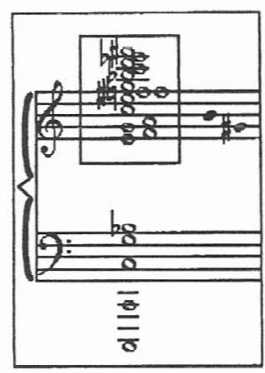

Cryste (compasso 43) allegro moderato - Abre-se sob o impacto da aparição do intervalo de terça menor descendente, $\mathrm{Si} / \mathrm{Sol}$ \#, nos sinos e tímpanos, dobrados por violoncelos, que passará a simbolizar o sofrimento de Cristo ao longo da missa. Neste intervalo, associado à insistência na repetição da célula rítmica, nasce todo o trabalho composicional desta seção.

Exemplo 6. Christe.

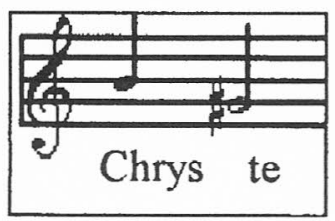


Em estilo responsório, alternando solos e coral, a textura orquestral também se agita, com trêmulos nas cordas que serão substituídos por uma figura de acompanhamento de arpejo em arco dos violoncelos, pedal harmônico nos contrabaixos e os sinos reforçando e enfatizando a veemência da prosódia da palavra Cryste. O responsório do coral é construído em quartas, enquanto os solos transitam pelos graus de um pseudo Sol \# menor (também construído sobre quartas justas).

Exemplo 7. Melodia do barítono solo construída sobre quartas justas.

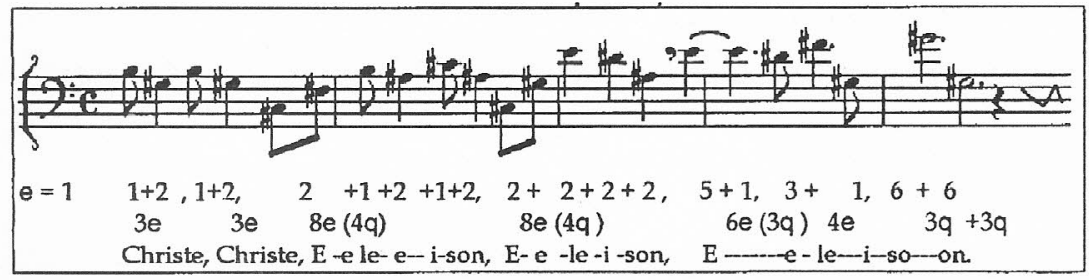

É interessante observar que, apesar da aparente regularidade do compasso quaternário simples, a rítmica não segue a métrica, mas a articulação das palavras: duas vezes Christe, em ternário, duas vezes Eleison, em binário, em seguida ênfase em Eleison, com a hemíola final. O tratamento prosódico-rítmico pode ser creditado tanto à tradição oriunda do Canto Gregoriano de auferir o ritmo a partir das palavras, quanto à formação nacionalista que seguia os preceitos de Mario de Andrade no que diz respeito à atenção à prosódia ${ }^{17}$. Este mesmo tipo de tratamento rítmico encontramos em obras de Camargo Guarnieri, onde os acentos e as articulaçõesa prevalecem sobre a métrica, com muita liberdade.

Um dos tratamentos transtonais pode ser observado nesta seção. $\mathrm{O}$ barítono emitiu, como vimos, um sol\# menor. A linha do baixo "acompanha" com sol\# frígio (sol\#, lá, si, lá, sol\# nos contrabaixos), o responsório do coral confirma Sol\# menor, com Dó \# no baixo, apesar de a linha

17. M. Andrade, 1927, "Ensaio sobre a Música Brasileira". O capítulo sobre ritmo reforça esta visão "medievalizante" do ritmo no cancioneiro popular tradicional. Por sua vez, Messiaen encontra na escrita neumática uma função libertadora da métrica e foi um dos elementos fundadores de sua formulação rítmica. Vide O. Messiaen, Traité de Rythme et d'ornitologie, Paris, Leduc, 1994, vol. IV. 
melódica dos sopranos ser construída sobre quartas (si, mi, lá, lá b). O baixo se move em direção a Fá menor. Soprano solo se incumbe do segundo Christe (comp. 50), criando ambigüidades através do reforço tético em torno de Dó, que se torna a terça menor de Lá menor na resposta do coro (comp. 56), mais uma vez com melodia nos sopranos em quartas (dó, fá, si b, lá). No terceiro Christe (comp. 57), duo de tenor solo e soprano solo, reforçado por sinos, sobre pedal de Fá \#, cria ênfases ascendentes, levando ao ponto culminante através do uso de saltos melódicos e contorno ascendente. Interessante observar que, enquanto o acompanhamento é estático, sobre o pedal Fá \#, as vozes listas movem-se incessantemente para cima, até que tudo se dissolve na resposta do coro num ambíguo Fá. Um pequeno interlúdio instrumental nas cordas, que começa com sinos repetindo a célula original, desta vez na terça maior de Dó menor (Sol/Mib). Trombones e trompas assumem a função dos sinos, reintroduzindo as terças menores e o cromatismo para um grande tutti que se abre sobre Mib menor em fortíssimo. A partir de compasso 96, o tímpano assinala Solb como uma senha de retomada da tranqüilidade. A textura se dissolve, levando a um sereno Christe enunciado pela última vez pelo coral, em Sol Maior/menor, que prepara a volta do Kyrie em Dó.

A tensão se dissipa aos poucos para retomar a placidez contemplativa do Kyrie, que segue a lógica de reapresentação das subseções na ordem inversa da primeira. Vai se tornando cada vez mais homofônico até se concluir grande tutti em Dó maior.

Este procedimento é comum a todos os movimentos, que terminam sempre numa tríade perfeita.

Podemos observar também aspectos de ordem da representação "emocional", subjetiva ou psicológica, da passagem. Como vimos, o Christe é introduzido pela terça menor, que no Crucifixus se confirmará como intervalo símbolo do sofrimento e da crucificação. Em contraste com o Kyrie, que é sempre plácido, altivo e sereno, a palavra Christe invoca tanto o sofrimento quanto a sua superação e a terça menor ou maior vai servir de sinal destas transformações.

\subsubsection{Gloria (con molta gioia e luce) Ré mixolidio}

Almeida Prado mantém a tradição de fazer do Gloria um grande movimento polifônico, onde predominam as imitações e as fugas. $\mathrm{O}$ 
material é introduzido pelos metais, sinos e primeiros violinos, que sustentarão as figuras de acompanhamento. $\mathrm{O}$ tema, apresentado pelos sopranos, será imitado à oitava por tenores, altos e baixos, em pontos diferentes da sua extensão, criando uma trama complexa criada pelo deslocamento das entradas, que são acompanhados pelas demais cordas.

Este tema de seis compassos, no modo de ré mixolídio, será trabalhado à maneira de um Cantus Firmus. A este tratamento escolástico somam-se recursos técnicos de permutação, oriundos do serialismo e considerando as apogiaturas como notas que fazem parte da coleção. Isto possibilita a criação de novos perfis e novas configurações rítmicas com o mesmo material.

Exemplo 8. Cantus firmus do Gloria.

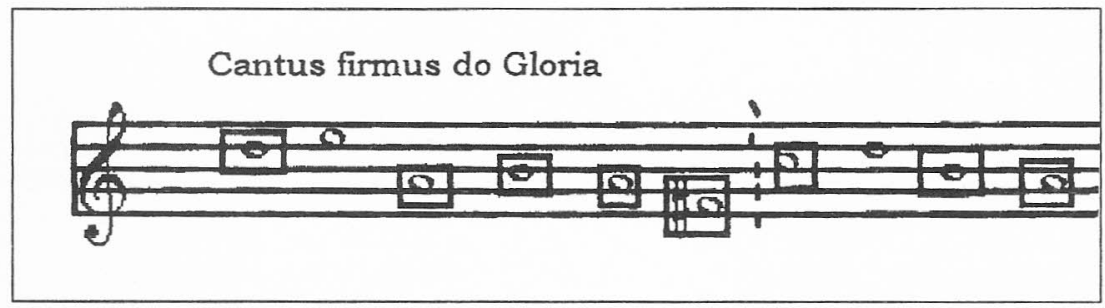

O movimento está subdividido em seções, algumas vocais, outras instrumentais. Todas elas elaboram o mesmo cantus firmus.

Seção 1. Gloria in excelsis Deo et in terra pax hominibus bonae voluntatis.

O longo texto apresenta problema de realização prosódica, que Almeida Prado resolve através da utilização de pequenas células rítmicas, repetidas e deslocadas.

Exemplo 9. Resolução rítmica do Gloria.

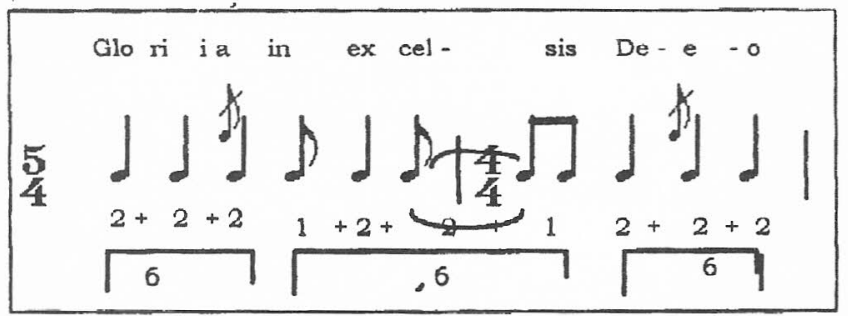


A configuração resultante apresenta um ritmo de caráter ternário, dançante, como encontramos, muitas vezes, na música religiosa de Bach. Se fizermos a analogia dos valores que encontramos nos doze primeiros tempos, considerando a colcheia como unidade, encontramos classes de intervalos muito próximas às da escala acústica: $\langle 2,2,2,1,2,2,1\rangle$.

Seção 2 (compasso 27). Laudamus te, benedicimus te, adoramus te, glorificamus te, gratias agimus tibi proper magnum tuam. Uma breve introdução instrumental, sopros e sinos, prepara a entrada de um canon para coro e orquestra, inclusive sinos e solo de soprano. Contrabaixos e violoncelos realizam, numa velocidade própria, bem mais lenta que os demais, uma espécie de pedal em round na escala sobre o II grau de ré, deslocando a atenção para um tom acima do modo original. Este canon utiliza as notas do cantus firmus em alturas fixas, congeladas, em valores aumentados e diminuídos entre si, com entradas que não são a distâncias regulares entre si, sobrepondo diversas prolações, como nas técnicas medievais em que todos participam simultaneamente do enunciado, e o canon é menos imitativo que cumulativo.

Seção 3. (compasso 59). Novo interlúdio instrumental, um fugato para cordas, com o tema original transposto à quinta, lá mixolídio. As entradas dão-se a um tom de distância cada: violino 1, lá; violino 2, si; viola, dó\#; violoncelo mi b. Mantém-se desta forma a proposta global da missa de privilegiar as relações de trítono. Esta intensificação da harmonia, que se encontrava "congelada" na seção anterior, leva ao retorno do tema principal do Gloria, em dó acústico.

Seção 4 (compasso 79). Domine Deus, Rex Celestis Deus patris Omnipotens, Domini folo unigenite Jesu Christe. Domine deus. Agnus dei, Filius patri, Agnus Dei.

Novo texto com material da primeira seção transposto a Dó. Basicamente homofônico, é cantado pelo coro, cabendo a melodia a sopranos e tenores, com acompanhamento de toda a orquestra, menos tímpanos e sinos. Esta seção se une ao Agnus Dei, que utiliza as mesmas células rítmicas e melódicas, que terão uma função importante na transição.

Seção 5 (compasso 103) Andante. Qui tollis peccata mundi, suscipe de precationem, qui sedes ad dexteram patris miserere nobis, tu solus dominus, tu solus altissimus, Jesus Christe cum sancto spiritu in gloria Dei patris, Amem. Em andamento bem mais lento, anunciado pelos tímpanos, cada solista tem uma frase, passando por um suposto si 
maior/menor. O tímpano, em Fá, anuncia o retorno à configuração rítmica e aos solos de soprano e tenor. O coro faz o responsório que, alternadamente com soprano solo e sinos, expõe pela última vez o tema do movimento que terminará no Amen em Ré maior.

Este movimento demonstra o domínio técnico da composição motívica e polifônica em Almeida Prado. Como numa sonata cíclica, os retornos dos materiais, as mudanças de caráter e a alternância de seções claramente delimitadas conduzem o ouvinte através dos diversos momentos da celebração da Gloria de Deus. O início giocoso torna-se gradativamente uma jubilosa contemplação em pianíssimo, em ressonância com os sinos. Antes do Amen final, os sinos confirmam as notas principais do motivo contido no cantus firmus.

Exemplo 10. Sinos do Gloria.

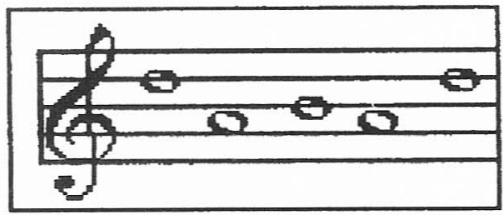

\subsubsection{Credo (solene e granítico) - Mi}

O Credo inaugura um novo ambiente, muito contrastante. O Kyrie e o Gloria são, respectivamente, a invocação e a glorificação de Deus. No Credo, as idéias de crença e fé surgem como uma conquista. Esta ruptura é representada por maior velocidade no andamento e um caráter mais duro. "Solene e granítico", o Credo se inicia por uma intervenção brutal de rulo de tímpano e trêmolo de violoncelos e contrabaixos, em crescendo, sobre Mi.

Seção 1. Credo in unun Deum alterna solo de barítono com solo de tenor e coro, sobre a escala descendente de mi com quinta diminuta. É este trítono que vai definir o caráter do modo utilizado neste movimento. Trata-se de uma escala construída com dois tetracordes frígios: mi, fá sol, lá e lá \#, si dó \#, ré \#. A configuração rítmica preserva muitas das características do Gloria, principalmente as três figuras iguais, entrecortada por uma apogiatura. O caráter solene e granítico e a marcha harmônica em relação ao Ré Maior do Amen, que fecha o movimento 
anterior, é evidente pelo ataque em fortíssimio, precedido de rulo de tímpanos e violoncelos e contrabaixos. O uníssono do Credo é enunciado três vezes, uma pelo solo do barítono, outra pelo solo do tenor e, por fim, pelo coral em uníssono. A quarta vez, já em piano, alterna barítono solo, seguido de coro, completando a escala descendente. O movimento segue alternando tenor e barítono em responsório com coral, sempre sublinhando os pedais. Os sinos têm uma função importante, anunciando as mudanças e sublinhando dramaticamente os momentos.

Exemplo 11. Escala simétrica do Credo.

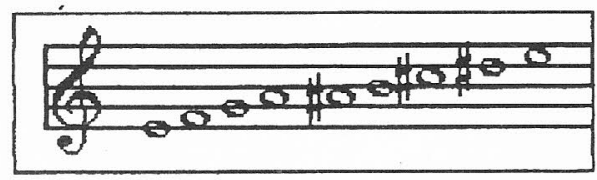

Exemplo 12. Tema descendente do Credo.

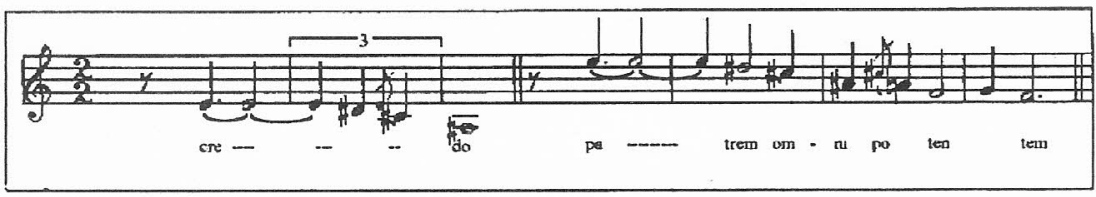

Seção 2 (compasso 62). Deum de deo transcorre num ambiente mais calmo. As cordas soltas são percorridas em toda a extensão, em glissandos contínuos. Sobre a camada de glissandos das cordas, soprano solo e sinos dialogam acompanhados dos instrumentos de sopro, em textura homofônica que sobrepõe quintas paralelas, imitando as cordas soltas das cordas. Contrabaixos enunciam uma grande escala descendente de Mi frígio que percorre lentamente a extensão da seção. Nesta seção, todo cromatismo é abandonado, com o solo de soprano percorrendo diferentes modalidades de Mi (maior, menor harmônico ou melódico, ou frígio natural). De fato, esta seção não é tonal, apesar de empregar procedimentos e escalas que pertencem ao sistema tonal. Esta ambiguidade é realizada através de vários procedimentos: simultaneidade de vários planos com concepções diferentes de $\mathrm{Mi}$, como quintas paralelas à distância de uma segunda maior (Mi e Ré), glissandos nas cordas soltas, uso de modos sem sensível, o baixo descendente com velocidade própria 
e, no final, um cluster em trinado, construído sobre a nota Mi no baixo, que reintroduz o tema frígio principal. Depois do grande cluster de coro e orquestra, a seção se encerra com solo de trompa, que recapitula o primeiro tema que vai conduzir a uma nova subseção contemplativa.

Seção 3 (compasso 121). Descendit del cielo, et incarnatus est desenrola-se a maior parte do tempo em textura homofônica,sobre o segundo tetracorde, o si frígio. Tem uma estrutura muito simples: escala descendente em terças paralelas sobre a escala descendente original, respondida pelo coral sobre o segundo tetracorde, soprano emite uma melodia ascendente sobre si menor frígio, que estaciona sobre Dó \# apenas para "resolver" Dó maior (compasso 144) para os tambores. A partir do compasso 147, antes do final da seção, os tímpanos apresentam um padrão rítmico ternário sobre a nota Dó, que serve de introdução a uma subseção instrumental.

Seção 4 (compasso 158). Calmo, gentile, con molta innocenza é uma seção instrumental, um solo de flauta sobre um ostinato de cordas, em estilo de uma Chacona de caráter pastoril. Como no tema principal do Gloria, uma frase longa é construída a partir de pequenas células rítmicas que serão elaboradas e deslocadas, construída sobre um Dó Maior genérico. $\mathrm{O}$ aspecto mais interessante desta seção, afora a beleza da melodia da flauta, é o padrão métrico assimétrico A melodia vai aos poucos sofrendo deslocamentos e pequenas variações, sem perder o padrão rítmico. Ao invés de 4 grupos de 3, o compasso quaternário composto usual, a métrica é subdividida em três grupos ternários, mais um grupo quaternário (13/8).

Exemplo 13. Tema em ostinato da Chacona.

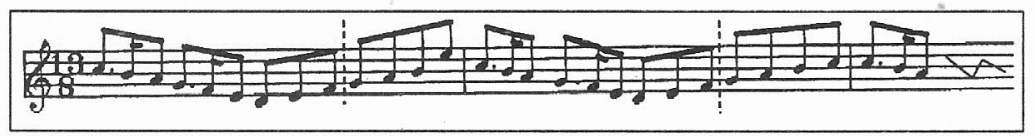

Esta seção prepara uma nova explosão passional quando a terça menor (Si/Sol \#) tocada pelos tímpanos assume a função de motivo do baixo da próxima seção, uma passacaglia. Aqui, a terça menor assume definitivamente seu papel de representar a dor e o sofrimento.

Seção 5 (compasso 176). Crucifixus . É um dos momentos mais dramáticos da missa. O ostinato dos tímpanos, com sua métrica peculiar de $9 / 8$ mais $4 / 8$, serve de motivo ostinato de uma passacaglia. 
Exemplo 14. O motivo da Passacaglia nos tímpanos.

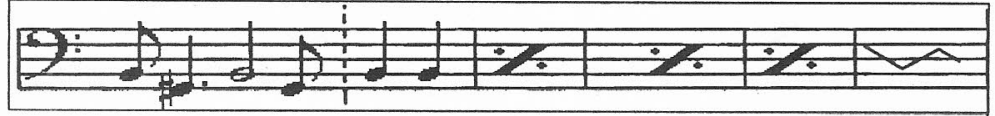

Um violoncelo solo sobrepõe-se à polifonia do coral com uma melodia que mistura as notas do motivo descendente do Credo com o ritmo da Chacona pastoril. O resultado é uma sobreposição politonal de planos sobre Mi frígio e Sol \# menor. Esta subseção leva à Ressurreição, Con molta luce, com os sinos tocando uma oitava diminuta e todos os instrumentos e vozes participando de um canto homofônico. O refrão do Crédo volta num duo de clarinete e soprano, onde tudo é mais uma vez confirmado, conduzindo ao final do movimento. Após uma pequena seção em parlando (et expecto ressurectionem mortuorum,....), com os sinos enunciando o motivo principal pela última vez, o Credo termina com um grandioso acorde em Mi Maior.

\subsubsection{Sanctus/hosanna}

Sanctus é o movimento mais curto de toda a missa. Entretanto, também é subdividido em pequenas seções, cada uma com caráter bem definido.

Seção 1. Introdução instrumental, com sinos comemorando jubilosamente, as cordas estabelecendo um acompanhamento em escalas descendentes, e trompas e trombones confirmando o baixo em fá. A figura de acompanhamento une num só desenho perfil descendente de ciaccona e o motivo ostinato da passacaglia.

Sanctus, sanctus, Dominus Deus, Sabaoth (compasso 12) - O coral invocará o Santificado três vezes, em uníssono, num desenho ascendente, que passa por grau conjunto de Fá para $\mathrm{F}$ \# e se encerra em Domine Deus, Sabaoth, num acorde que sobrepões terças a partir de Dó no baixo, criando um acorde politonal.

Seção 2 (compasso 23). Pleni sunt caeli, et terra gloria tua adagio. Apenas dez compassos de adagio, dueto de barítono solo e soprano solo, interrompidos pelos sinos que introduzem o repicar de Hosanna.

Seção 3 (compasso 33). Hosanna traz de volta o clima, o chamamento à celebração, com os sinos liderando um canon que se tornará o centro temático do movimento. 
Exemplo 15. Repicar dos sinos de Hosanna.

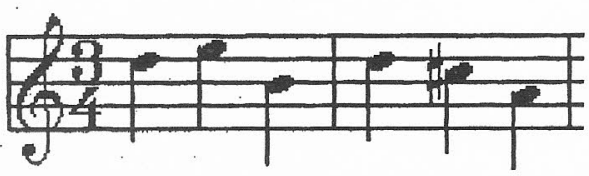

Seção 4. Benedictus (compasso 46), um adágio lindamente contemplativo, construído sobre a escala acústica de Dó, apenas com o objetivo de chamar o Hosanna de volta.

Seção 5 (compasso 33). Hosanna da capo. Encerramento sobre acorde de Lab7.

Do ponto de vista dos materiais harmônicos, este é o menos estável de todos os movimentos. Cada pequena seção tem uma fundamental própria: Fá, Fá \#/Dó; Dó/Lá; Lá b7, retardando a confirmação de Fá para o último movimento, o Agnus Dei.

O material principal deste movimento, o repicar dos sinos, também foi extraído do material do Cantus Firmus do Gloria, havendo, apenas, uma reconfiguração entre notas principais e notas "melódicas".

\subsubsection{Agnus Dei}

Este é o movimento final da missa. Seu significado é Cordeiro de Deus, limpai os pecados do mundo. Após a celebração e a consagração do Divino, do Santo e do Abençoado, o olhar volta-se para os humanos e seus pecados. O clima é de submissão, introduzido por uma andante molto cantabile e amoroso, de caráter introspectivo. Cordas e solistas, que aos poucos vão sendo acompanhados pelo coral e sopros, em textura imitativa, movem-se em torno de terças. Gradualmente, terça se desdobrando em terça, as fundamentais das tríades que vão sendo formadas vão se deslocando e podem estabilizar-se sucessivamente sobre Lá, ou Fá, ou Ré, ou Si (Fá). Esta ambiguidade é ainda mais exacerbada através da introdução de terças maiores ou menores, nas tríades que se foram formando e, aos poucos, um tutti poliacordal aparece para o Miserere Nobis.

Este tratamento harmônico, muito próximo do tonal, enfatizando as relações triádicas, é bastante representativo da técnicas harmônicas empregadas na Missa. Todo o movimento tem como nota fundamental o Fá. Entretanto, cada pequena seção elabora melódicamente e harmônicamente suas características locais. Os fatores de tensão e de resolução 
de tensão são introduzidos principalmente por relações de segunda menor e através de trítonos. Após um início plácido sobre a fundamental Fá, a tensão aumenta, o perfil se agita para, em seguida, estabilizar-se definitivamente sobre Fá.

No exemplo 16, uma redução dos pontos harmônicos mais importantes do movimento, com aumento de tensão e subseqüente distensão. As notas em branco são "fundamentais", conduzem a harmonia a partir do baixo, e as notas em preto são polarizações e acordes de caráter transitório.

Exemplo 16. Relações triádicas e não triádicas do Agnus Dei.

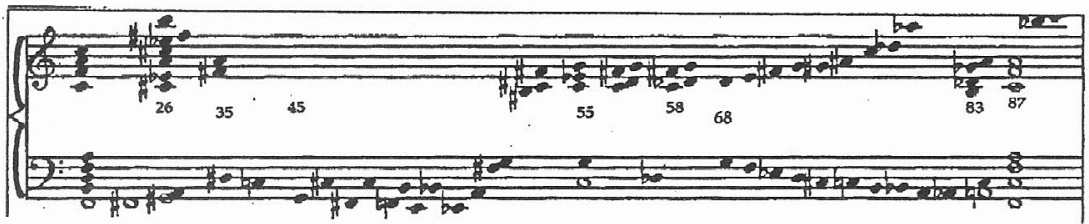

A partir do compasso 90 toda a textura e a harmonia se estabilizam. Ao aproximar-se do final, o Fá Lídio torna-se cada vez mais claro, com os sinos tocando um acorde de Fá Maior, e o último enunciado do solo de barítono é claramente uma frase descendente em fá lídio: dona nobis pacem.

Exemplo 17. Último enunciado da Missa, em Fá lídio.

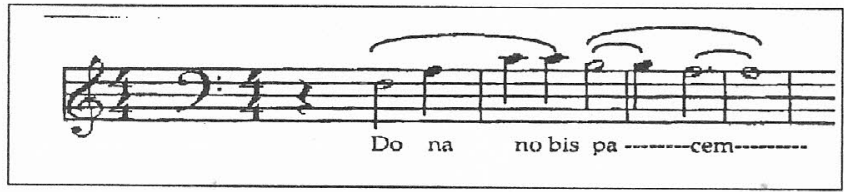

\section{Conclusões}

Esta análise está longe de ser uma análise completa da Missa de São Nicolau. Procuramos ressaltar alguns aspectos que pareceram importantes dentro das questões que se têm colocado para nós nos últimos anos. Entre elas, a retomada de uma vertente teórica harmônica, que podemos considerar de origem "rameauniana". Nesta vertente, a idéia de um baixo fundamental, gerador da harmonia, predomina sobre a idéia de sobreposição de intervalos resultantes de condução de vozes. O emprego 
destas técnicas harmônicas, que Almeida Prado chamou de transtonais, não o impediu de alternar na composição da Missa seções mais verticais e seções mais horizontais, de caráter polifônico, numa espécie de sincretismo entre as tradições européias de origem francesa e as tradições consideradas brasileiras, na medida em que Mario de Andrade recomendava o tratamento polifônico à harmonia. Este caráter sincrético, entretanto, não se manifesta através de estereótipos que podem ser identificados imediatamente. Mesmo materiais de origem afro-brasileira, como os orixás das escalas e dos ritmos do Credo, recebem tratamento estilizado e formalizado.

A natureza do som em suas relações com a percepção tem sido debatida historicamente. A partir da primeira metade do século XX, a Escola de Viena e seus seguidores serialistas e pós seriais defendem o trabalho motívico e a ordenação e permutação intervalares como suficientes para a criação de estruturas profundas de organização da superfície. As vertentes mais conservadoras acusavam a primeira de falta de fundamentação harmônica, mantendo-se, em maior ou menor medida, mais próximas das estruturas harmônicas tonais. A "solução" Messiaen, por sua vez, baseada numa tênue semelhança entre a percepção e as "ressonâncias naturais", abria duas possibilidades, apontava em duas direções. Uma, na direção da desintegração do som em seus componentes físicos, como para os compositores que adotaram as técnicas espectrais. Outra, na direção de uma reformulação das funções harmônicas em seus componentes diatônicos e cromáticos, dentro do temperamento igual.

Almeida Prado optou claramente pelo segunda. Após os anos mais colorísticos da década dos 70, Almeida Prado aproximou as diferentes experiências de sua formação. Esta aproximação se deu tanto do ponto de vista da utilização de modos e escalas, quanto das durações e ritmos, e ainda o das texturas. Os modos simétricos, de transposição limitada, os acordes de ressonância estão presentes, mas contextualizados dentro da tradição da igreja católica e, por sua vez, podem ser aproximados dos modos regionais brasileiros. Os ritmos de tradição afro-americana são tratados como os modos rítmicos ou pedais rítmicos de Messiaen que, por sua vez, aproximam-se das técnicas medievais e renascentistas como canones, chaconas e passacaglias. Os procedimentos de permutação motívica também estão presentes, sincretizados com o tratamento tradicional de cantus firmus. Do ponto de vista das texturas, encontramos 
desde técnicas homofônicas em uníssono até construção em "cunha" de clusters e tutti e acordes densamente cromáticos, passando pelas técnicas polifônicas as mais variadas.

Outro aspecto importante é o respeito às tradições do rito católico. A tradição católico-romana palestriniana foi inteiramente respeitada, principalmente no que diz respeito à clareza na enunciação do texto e à estrutura retórica de três invocações em cada momento dramático do rito.

Além destes aspectos técnicos, meu interesse pelas diversas tendências composicionais da música brasileira nas últimas décadas e sua inserção no campo mundial da composição contemporânea atraíame para determinados aspectos considerados empíricos, no sentido da experiência sensível e da experiência de vida dentro de um determinado grupo cultural. A trajetória da obra de Almeida Prado, além de suas características pessoais, presta-se a este tipo de abordagem.

O desafio para quem se propõe a fazer análise musical tem sido o de encontrar formas de acesso a um repertório resistente às formas tradicionais de composição. Para o período que se convencionou chamar de pós-tonal, a praxe tem sido o uso das diversas formas de Set Theory, que identifica, analisa e interpreta as estruturas estruturais subjacentes, do ponto de vista dos conjuntos de classes de notas e de classes de intervalos. Mas, como vimos, nem a composição em suas técnicas, nem as análises são atividades neutras. Elas implicam, por parte de quem analisa, uma avaliação das pertinências de cada obra. Nesta Missa, levando em consideração os fatores culturais da formação de Almeida Prado e o mundo sonoro ao qual ele esteve exposto, consideramos que o aspecto qualitativo da harmonia timbrística não poderia deixar de ser tomado em consideração.

Entretanto, do ponto de vista da teoria para a classificação dos acordes e das escalas surgiram algumas dificuldades. Estas dificuldades encontram-se não apenas na identificação correta, mas também na ruptura de algumas das convenções básicas da teoria musical:

1. a equivalência entre oitavas, traço comum tanto da convenção tonal como na pós tonal, não se aplica.

2. a inversão de acordes e o conceito tradicional de tríades também não se aplicam, apesar do uso extensivo de relações triádicas encontradas ao longo da Missa. 
Mesmo conscientes destes aspectos, optamos por descrever do ponto de vista das escalas e dos modos que encontramos, apesar da extrema ambigüidade das classificações, uma vez que tanto as escalas quanto o baixo e os acordes estão efetivamente na partitura. Este aspecto traz à tona outros componentes da atividade musical, que são os mecanismos de apreensão, interpretação e criação de realidades.

O músico se torna músico através da escuta. Ou seja, é a música que nos converte em músicos. Nossa cultura letrada, por outro lado, torna conscientes, e grafáveis, níveis mais profundos de estruturação, que só têm paralelo nos níveis considerados inconscientes ou inteligíveis da cognição. Ou seja, a música é capaz de trazer para o nível do sensível operações que se passam no nível do inteligível. Como este "inconsciente" ou nível profundo se organiza tem sido objeto de várias correntes das ciências sociais, humanas e naturais. Podemos afirmar que estão envolvidas neste processo pelo menos a psicologia e a psicanálise, a biologia, a antropologia, a sociologia, a linguística e as ciências exatas, se pensarmos na formalização e quantificação das informações.

Quando nos debruçamos sobre a escuta e a leitura de uma partitura e de sua atualização no intuito de interpretá-la, seja no sentido da performance, seja no sentido da cultura, procuramos verificar em que medida a experiência empírica tem operado tanto na tarefa do compositor quanto na experiência de quem analisa. Foi neste sentido que nosso trabalho partiu da superfície do fato musical e descrevê-lo tornou-se uma tarefa em que a linguagem opera por seleção e classificação.

Caberá ao leitor reconhecer esta forma como a mais adequada e a mais próxima da experiência da própria Missa.

Em qualquer um dos casos, espero ter preservado a dignidade da obra dentro dos impasses que se têm apresentado aos músicos e à cultura nas últimas décadas ${ }^{18}$.

18. A pesquisa Implicações Estéticas da Música Brasileira nos Anos 70 e 80 foi parcialmente financiada pelo CNPq. A análise da Missa de São Nicolau é integrante da pesquisa de pós doutorado realizada na Universidade de Columbia, com financiamento da CAPES. 